\title{
Laboreal
}

Volume $11 \mathrm{~N}^{\circ} 1$ | 2015

Modos de vida e trabalho

\section{Saúde, gênero e trabalho nas escolas públicas: potencialidades e desafios de uma experiência com o dispositivo "Comunidade Ampliada de Pesquisa e Intervenção"}

Salud, género y trabajo en las escuelas públicas: potencial y desafíos de una experiencia con el dispositivo "Comunidad Ampliada de Investigación e Intervención"

Santé, genre et travail dans les écoles publiques: potentiels et défis d'une expérience avec le dispositif «Communauté Élargie de Recherche et Intervention "

Health, gender and labor in public schools: potentialities and challenges of an experience with "Extended Research and Intervention Community"

Mary Yale Neves, Hélder Pordeus Muniz, Edil Ferreira da Silva, Joana Dar'k Costa, Jussara Brito e Milton Athayde

\section{CpenEdition}

\section{Edição electrónica}

URL: http://journals.openedition.org/laboreal/4169

DOI: 10.4000/laboreal.4169

ISSN: 1646-5237

Editora

Universidade do Porto

Refêrencia eletrónica

Mary Yale Neves, Hélder Pordeus Muniz, Edil Ferreira da Silva, Joana Dar'k Costa, Jussara Brito e Milton Athayde, "Saúde, gênero e trabalho nas escolas públicas: potencialidades e desafios de uma experiência com o dispositivo "Comunidade Ampliada de Pesquisa e Intervenção" », Laboreal [Online], Volume $11 \mathrm{~N}^{0} 1$ | 2015, posto online no dia 01 julho 2015, consultado o 09 outubro 2019. URL : http:// journals.openedition.org/laboreal/4169; DOI : 10.4000/laboreal.4169

Este documento foi criado de forma automática no dia 9 outubro 2019 


\section{Saúde, gênero e trabalho nas escolas públicas: potencialidades e desafios de uma experiência com o dispositivo "Comunidade Ampliada de Pesquisa e Intervenção"}

Salud, género y trabajo en las escuelas públicas: potencial y desafíos de una experiencia con el dispositivo "Comunidad Ampliada de Investigación e Intervención"

Santé, genre et travail dans les écoles publiques: potentiels et défis d'une expérience avec le dispositif «Communauté Élargie de Recherche et Intervention "

Health, gender and labor in public schools: potentialities and challenges of an experience with "Extended Research and Intervention Community"

Mary Yale Neves, Hélder Pordeus Muniz, Edil Ferreira da Silva, Joana Dar'k Costa, Jussara Brito e Milton Athayde

NOTA DO EDITOR

http://dx.doi.org/10.15667/laborealxi0115myn1

Manuscrito recebido em: Novembro de 2014

Aceite após peritagem: Abril de 2015 


\section{Introdução}

1 O objetivo do texto é apresentar a análise que efetuamos de uma das experimentações do Programa de Formação em Saúde, Gênero e Trabalho nas Escolas ${ }^{[1][2]}$, desenvolvido no Brasil no período de 2001 a 2010, assim como de seu dispositivo metodológico, denominado Comunidade Ampliada de Pesquisa e Intervenção (CAPI) ${ }^{[3]}$. Trata-se da pesquisa-formação-intervenção realizada na cidade de João Pessoa, capital do estado da Paraíba, junto às trabalhadoras de escolas públicas do ensino fundamental (professoras, merendeiras - na verdade cozinheiras, auxiliares de serviços gerais, diretoras etc. $)^{[4]}$, sinalizando para suas potencialidades, dificuldades e desafios.

2 O Programa de Formação foi pensado como um meio para desenvolver a capacidade de compreender $\leftrightarrow$ transformar as relações entre o trabalho na escola e os processos de subjetivação e de saúde/doença, com base no diálogo-confrontação entre o conhecimento científico e o saber engendrado na experiência prática das trabalhadoras. Concebeu-se um dispositivo de formação para pesquisa-intervenção em rede: um programa de formação articulado a um programa de pesquisas. Ou seja, uma formação voltada para a ação compreensivo $\leftrightarrow$ transformadora, tendo como meta lutar pela saúde e afirmar a potência da vida, incorporando a ótica das relações sociais de gênero (Hirata, 1993, 2002; Kergoat, 2010). A expectativa era de que a participação nesse Programa contribuísse para aguçar o olhar e a escuta das trabalhadoras (e dos investigadores profissionais) para os problemas da escola em sua relação com a sua saúde, como também ajudasse a descobrir as possibilidades de saída e de construção de um trabalho que compatibilizasse produtividade e qualidade com saúde (Brito, Athayde \& Neves, 2003a, 2003b; Brito \& Athayde, 2003).

Dentre os aportes que foram fundamentais na composição da caixa de ferramentas epistemológica, teórica e metodológica do Programa de Formação, destacaremos no caso deste artigo, principalmente, as contribuições vinculadas às formas de pesquisaintervenção desenvolvidas a partir do Modelo Operário Italiano (MOI) de produção de conhecimento e luta pela saúde, pautadas em um determinado regime de produção de saberes para compreender $\leftrightarrow$ transformar as relações entre saúde, subjetividade e trabalho (Vincenti, 1999; Muniz, Brito, Souza, Athayde \& Lacomblez, 2013). De acordo com Oddone, Re e Briante (1981), o MOI interpreta a realidade com base nos saberes ditos formais e informais. Nesta experimentação engendraram o conceito de Comunidade Científica Ampliada, apontando para um dispositivo caracterizado pela colaboração entre os saberes gerados a partir da experiência dos protagonistas do trabalho e da prática científica dos pesquisadores profissionais, tendo em vista a construção de um saber viabilizador e agenciador da compreensão e intervenção em saúde nos locais de trabalho (Oddone et al., 1986).

Outra referência adotada concerne às reflexões e orientações presentes na proposta de um Dispositivo dinâmico de três polos (DD3P), reconfiguração desenvolvida por Schwartz (2000a, 2000b, 2010) a partir da experiência italiana, em uma démarche ergológica. Este autor faz algumas críticas à noção de comunidade científica ampliada. Schwartz (2000a) sinaliza que o vocábulo "científica" pode gerar imprecisões ao afirmar o primado do conhecimento científico, restringindo as riquezas e possibilidades de outras formas de pesquisa e produção de saberes, como aquelas oriundas da experiência dos trabalhadores. Dessa forma, alerta que é preciso ter mais clareza acerca das exigências e responsabilidades tanto dos pesquisadores profissionais quanto dos trabalhadores. 
Para esse autor, além dos polos que envolvem os saberes das disciplinas e os saberes investidos na atividade, é imprescindível considerar um terceiro polo que regula a colaboração e o confronto entre esses dois: o polo ético-epistêmico. Trata-se, para o referido autor, de um polo presente-ausente na experimentação do MOI: presente na prática, operado pelos sindicatos, ausente em sua teorização. Essa colaboração multi/ transdisciplinar e interprofissional exige uma postura de humildade epistemológica, geradora de desconforto intelectual, demandando disposição para retrabalhar tanto os conceitos das disciplinas quanto os saberes da experiência. Torna-se fundamental evitar uma postura de exterritorialidade e enfrentar o debate de normas, considerando um mundo de valores presentes nas situações de trabalho. É preciso constantemente discutir o sentido da intervenção e pesquisa em situações de trabalho, levando-se em conta as seguintes questões: podemos intervir na vida dos outros? Em que condições? A partir de quais valores? Assim, é de fundamental importância a definição dos saberes e valores implicados num processo de formação que se dá no interior desse dispositivo de colaboração (Brito, 2004).

5 Nessa perspectiva, ao focar a questão envolvendo saúde, subjetividade e trabalho nas escolas, acreditamos que o processo de incorporação das trabalhadoras em um dispositivo de compreensãor $\leftrightarrow$ transformção, estabelecendo um espaço dialógico que facilite o debate entre experiência e conhecimento científico, não apreendia as trabalhadoras como consumidoras passivas, meras aprendizes-repetidoras do que ouviram dos profissionais de formação e investigadores profissionais (Freire, 1983, 1996). Tratava-se, isto sim, de mútua aprendizagem, a partir de suas culturas e mútuas inculturas (Schwartz, 2000a, 2010), podendo-se fazer na prática essa confrontação, validando/invalidando, desenvolvendo as informações disponibilizadas e discutidas. Em suma, foi principalmente a partir dessas contribuições que se constituiu no Programa de Formação em Saúde, Gênero e Trabalho nas Escolas o dispositivo que denominamos Comunidade Ampliada de Pesquisa e Intervenção - CAPI (Brito, Athayde \& Neves, 2003a; Brito \& Athayde, 2003), em especial operacionalizado por Encontros sobre o Trabalho (Schwartz, 2000b, 2010) ${ }^{[3]}$.

6 Segundo a premissa de que há sempre uma defasagem entre tarefa prescrita e atividade (Teiger \& Daniellou, 1987; Guérin, Laville, Daniellou, Duraffourg \& Kerguelen, 2001), a démarche ergológica vai valorizar como os saberes são produzidos e os valores são retrabalhados na atividade humana. Esta última é compreendida como sempre envolvendo um embate de normas, considerando o mundo de valores que aí circulam. Desse modo, não se trata de formar no sentido de formatar, efetuar um enquadramento, mas de possibilitar um espaço de mobilização do ponto de vista da atividade, com sua complexa dinâmica (Schwartz, 2010). Mas como construir um processo de formação que leve em consideração esse ponto de vista (da atividade)? o encaminhamento dado pelo referido Programa, em consonância com o paradigma da formação dos atores na e pela análise do trabalho, para e pela ação apontado a partir de estudos ergonômicos (Teiger \& Daniellou, 1987; Teiger \& Laville, 1991; Teiger \& Lacomblez, 2007, 2013), procura desenvolver um processo de formação na produção de dispositivos de análise e transformação do trabalho dirigido pelas próprias trabalhadoras (desenvolvendo sua capacidade investigativa), em diálogo com os investigadores profissionais. Ou seja, ao longo da formação proposta, análises do trabalho e propostas de ações para mudanças foram engendradas coletivamente, 
resultantes de uma maquinação dialógica, desenvolvida em uma comunidade ampliada de pesquisa e intervenção.

7 Durrive (2010), conforme a démarche ergológica, aponta que é preciso construir dispositivos de formação que facilitem esse processo e que coloquem em análise os embates presentes na atividade dos trabalhadores, entre a heterodeterminação com relação às normas antecedentes e a sua capacidade de produzir novas normas (Schwartz, 2000b, 2010). Ele denomina Ergoformação a perspectiva que procura colocar em sinergia os saberes e valores investidos na atividade, buscando o exercício de apreender o que escapa da dimensão formal do ofício e do emprego para, a partir daí, produzir férteis questões. Sinaliza ainda que o trabalhador, individualmente, tem dificuldade de construir o ponto de vista da atividade, sugerindo para tanto a construção de encontros sobre o trabalho que produzam a confrontação de saberes e valores diferentes, visando à compreensão e transformação da atividade.

\section{O Programa de Formação e a constituição de Comunidades Ampliadas de Pesquisa e Intervenção (CAPIs)}

8 De acordo com sua proposta epistemológica e metodológica (Brito, Athayde \& Neves, 2003a, 2003b; Brito \& Athayde, 2003), o Programa foi estruturado em ciclos: as trabalhadoras que participavam de um determinado ciclo de formação passavam a assumir a responsabilidade de formação de novas trabalhadoras, tornando-se deste modo "multiplicadoras". O papel da equipe de investigadores profissionais, a partir desse momento, passava a ter o papel de apoio do processo, acompanhando tecnicamente o momento formativo e aprendendo/avaliando/reformulando o conhecimento produzido. Em sequência, cada novo grupo de multiplicadoras estaria preparado para, em novos ciclos, formar sucessivamente outras trabalhadoras, buscando reproduzir (de forma sempre singular) as duas fases (primeiro um curso, seguido pelo retorno às escolas para a realização de estudos de campo, com encontros sistemáticos da CAPI) que compunham cada ciclo, conforme representado na Figura 1. Ao movimento - de ida às escolas e retorno à CAPI - denominamos alternâncias, com base no método de educação de adultos classicamente designado formação em alternância (Brito, Athayde \& Neves, 2003a; Merhan, Ronveaux \& Vanhuille, 2007).

Figura 1: Fases previstas em cada ciclo de formação

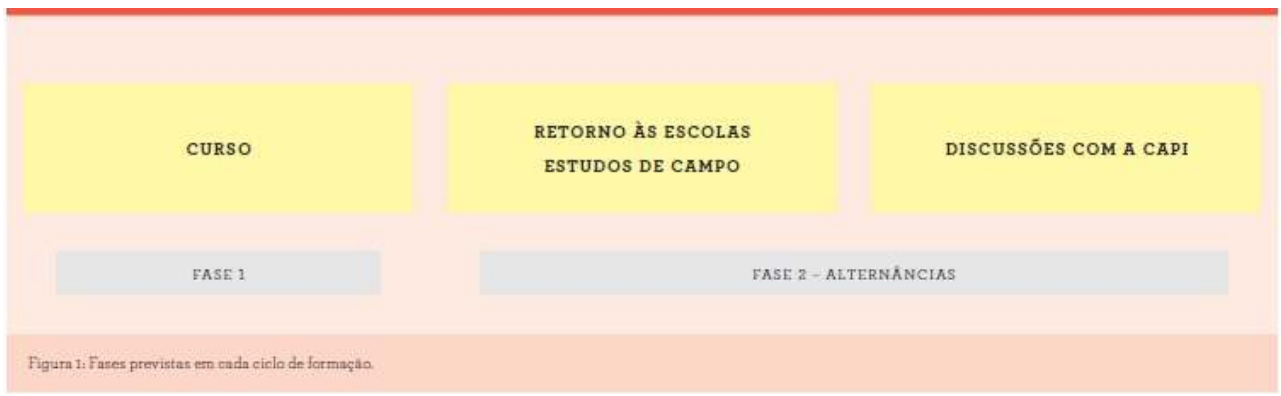

Dessa forma, cada ciclo envolveu duas fases:

a. $1^{\mathrm{a}}$ fase: curso de formação de multiplicadoras em saúde, gênero e trabalho nas escolas. Este curso, ao contrário de algo estanque, foi concebido como um processo contínuo de diálogo/ 
confrontação entre o polo das disciplinas científicas sobre a temática e o da experiência engendrada na prática cotidiana do trabalho, possibilitando a emergência de novos conhecimentos e desenvolvimentos mútuos. O curso envolveu a apresentação de conceitos considerados como necessários e fundamentais para abordar as relações entre trabalho, saúde e gênero, o que foi feito por intermédio de exposições, estudos de textos e debates em subgrupos e no grupo maior (que reunia trabalhadoras e investigadores profissionais), no qual aquelas eram provocadas a discorrerem acerca de suas experiências, para confrontá-las com os conceitos. Dentre os principais conceitos trabalhados, podemos ressaltar trabalho como atividade (Guérin et al., 2001; Schwartz, 2000), saúde como normatividade (Canguilhem, 1995) e relações sociais de gênero /divisão sexual do trabalho (Hirata, 2002; Kergoat, 2010). A equipe de investigadores profissionais selecionou temas geradores (Freire, 1983) da discussão e do processo de formação, que foram reunidos em um Caderno de Textos (Brito, Athayde \& Neves, 2003b), cujo conteúdo é apresentado por meio de perguntas e respostas pertinentes a cada um deles, tais como comunidade ampliada de pesquisa, saúde, gênero, gestão, trabalho na escola e riscos para a saúde e readaptação profissional. Acreditamos que através de uma Pedagogia da Pergunta (Freire \& Faundez, 2002) vai-se produzindo um movimento dialógico, cujo efeito visado é o de maior envolvimento e desenvolvimento (individual e coletivo) das participantes, que eram estimuladas também a formular questões sobre o tema tratado. Para finalizar essa primeira fase, as últimas sessões do curso eram reservadas para a discussão e programação do desenvolvimento do Programa - o que implicava na definição de focos de atenção para os exercícios de estudo de campo ( $2^{\mathrm{a}}$ fase), com base na análise das discussões realizadas nos subgrupos e no grupo maior. Escolhidos os focos, passava-se ao momento de definição das estratégias e procedimentos de estudo a serem utilizados nos exercícios.

b. $2^{\text {a }}$ fase: retorno das multiplicadoras às escolas para a realização de exercícios de estudo de campo centrados nos focos previamente definidos. Esse era um momento crucial para o Programa, pois era nele que se começava a expandir a Comunidade Ampliada de Pesquisa e Intervenção, pela trama engendrada em cada escola - exatamente quando as trabalhadoras se iniciavam no processo de investigação.

10 Os exercícios de campo eram seguidos de sistemáticos Encontros Sobre o Trabalho da CAPI visando a discussão sobre a experiência (procedimentos utilizados, dificuldades encontradas para a produção de informações, análise e elaboração de relatórios a serem entregues e apresentados mensalmente nos Encontros da CAPI, etc.), os materiais gerados e as possíveis mudanças a serem experimentadas e eventualmente reivindicadas para toda a rede de ensino. A ideia era proporcionar nesses Encontros o constante movimento de convocação e validação dos saberes, por meio da criação de diferentes momentos de sua confrontação (Schwartz, 2010; Durrive, 2010). A expectativa era ainda de que os materiais produzidos pudessem alimentar um Observatório sobre as relações entre saúde, gênero e trabalho nas escolas, permitindo seu monitoramento contínuo.

\section{A experimentação em João Pessoa (Paraíba)}

11 O Programa de Formação teve uma conformação peculiar na cidade de João Pessoa (região nordeste do Brasil), que o diferencia em parte da experiência realizada no estado do Rio de Janeiro. Uma das diferenças está no fato de que no Rio de Janeiro o Programa surgiu de uma demanda do sindicato. Já na capital paraibana, esta foi se construindo a partir do momento em que um grupo de investigadores profissionais procurou o Sindicato dos Trabalhadores da Educação do Município de João Pessoa 
(Sintem/JP) para propor a criação de um programa de pesquisa e formação e convidá-lo para desenvolvê-la juntamente com as trabalhadoras das escolas públicas municipais. Após sua aprovação pelo Congresso dos Trabalhadores em Educação, em 2001, os dirigentes do sintem e a equipe de investigadores profissionais organizaram e encaminharam a fase inicial do primeiro ciclo do Programa - o curso de formação das primeiras multiplicadoras (Neves, Brito \& Athayde, 2010).

\subsection{A formação das multiplicadoras}

O primeiro grupo de participantes do curso, num total de quinze trabalhadoras representando doze escolas, foi composto de três diretoras, seis professoras, duas merendeiras, duas orientadoras educacionais, uma inspetora de alunos e uma psicóloga educacional. Destas, três eram dirigentes sindicais. Conforme planejamento do curso, foram constituídos subgrupos com trabalhadoras para leitura e discussão sobre a temática em questão, com a coordenação de um membro da equipe de investigadores profissionais, cuja função era estritamente focalizar e favorecer a discussão entre elas. Além de um coordenador, tínhamos a presença de mais dois auxiliares de pesquisa, cujo papel consistia em registrar o modo de funcionamento de cada subgrupo e viabilizar as suas condições de realização (gravação, etc.). No momento seguinte, essas discussões eram socializadas e ampliadas em plenária da CAPI, propiciando a confrontação entre os conceitos das disciplinas científicas e os saberes da experiência. O último dia foi dedicado à escolha e discussão dos focos dos estudos de campo que seriam realizados por essas trabalhadoras nas escolas e apresentados nos Encontros da Comunidade Ampliada de Pesquisa e Intervenção. Os focos definidos foram: o espaço de trabalho; a sobrecarga e as pressões do trabalho; a dinâmica das relações psicológicas e sociais no trabalho; $e$ os sinais de sofrimento/adoecimento e formas de enfrentamento.

13 A segunda fase da formação teve por finalidade a realização do diagnóstico das situações de trabalho pelas trabalhadoras (através dos estudos de campo, tendo um foco como objeto de investigação), a discussão dos materiais produzidos (por meio de encontros mensais, no total de quatro, com a CAPI), além da criação de possíveis soluções para os problemas encontrados. Um segundo momento de cada um desses encontros era reservado para a escolha e o planejamento (em subgrupos) do exercício de estudo de campo do foco seguinte ${ }^{[5]}$. É importante ressaltar que, nessa segunda fase, as trabalhadoras tiveram (quando solicitado) apoio sistemático por parte dos auxiliares de pesquisa. Esse acompanhamento foi realizado mediante visitas às escolas participantes do Programa, com o objetivo de apoiar as trabalhadoras no estudo de campo, auxiliando na escolha dos procedimentos e instrumentos metodológicos, na organização dos materiais gerados, bem como na sua preparação das apresentações dos focos pesquisados nos Encontros da CAPI.

Vale assinalar que os materiais apresentados nestes Encontros passavam em seguida por um processo de sistematização realizado pela equipe de investigadores, para serem debatidos nos Encontros subsequentes, com vistas à sua validação, refutação, ampliação pelas trabalhadoras. A partir daí buscavam-se, conjuntamente, formas de enfrentamento para as questões e problemas detectados nos locais de trabalho.

No último Encontro, foi realizada uma avaliação na qual as trabalhadoras ressaltaram a importância de fazerem parte de um Programa que visava melhorar as condições e formas de organização do trabalho nas escolas, a partir da incorporação das próprias 
trabalhadoras como sujeitos ativos agenciadores desse processo. Em vários momentos também reafirmavam o compromisso de se engajarem efetivamente na formação subsequente das "trabalhadoras de base ${ }^{[6]}$ ", momento em que atuariam como "multiplicadoras". Essas trabalhadoras-multiplicadoras se dividiram em duplas para, juntamente com algumas militantes sindicais, realizarem visitas às escolas por elas selecionadas, com o objetivo de convidarem novas trabalhadoras para participarem do Programa de Formação. Foram constituídos, assim, dois novos grupos compostos por vinte e nove trabalhadoras, representantes de dezenove escolas (que, junto com as primeiras multiplicadoras de doze escolas, contabilizaram um total de vinte e sete escolas e de quarenta e quatro trabalhadoras que integraram o referido Programa $)^{[7]}$.

Dos dois novos grupos, apenas três participantes eram do sexo masculino, sendo o conjunto formado também por diferentes categorias profissionais. As trabalhadorasmultiplicadoras participaram desses grupos como "facilitadoras"[8] da discussão, juntamente com membros da equipe de investigadores profissionais. Após a primeira fase (curso), as trabalhadoras de base iniciaram a fase dos exercícios de estudo de campo em suas respectivas escolas.

No final do segundo curso, todas as participantes foram convidadas a escrever acerca das experiências de formação no estado do Rio de Janeiro e em João Pessoa, ou sobre temas de sua escolha. Algumas aceitaram o convite formulado e o Caderno de Relatos de Experiências foi publicado com textos de trabalhadoras pertencentes a diferentes categorias profissionais da escola (Brito et al., 2003c).

\subsection{Observatório das condições de saúde e trabalho nas escolas}

De acordo com a proposta original, um dos desdobramentos apontados pelo Programa de Formação era de que os materiais produzidos pelas trabalhadoras ao longo do seu desenvolvimento subsidiassem um Observatório sobre as relações entre saúde, gênero e trabalho nas escolas. Para tanto, em uma terceira fase, optamos em João Pessoa por realizar análises e intervenções mais sistemáticas que envolvessem o conjunto das trabalhadoras de cada uma das escolas até então vinculadas ao Programa. Tal proposta visava a que o Observatório possibilitasse às próprias trabalhadoras, de forma autônoma, uma vigilância contínua, permanente e autônoma das suas condições e formas de organização do trabalho, tendo por objetivo a promoção da saúde a partir das situações de trabalho (Silva, Brito, Athayde \& Neves, 2009). Depois de selecionadas as escolas que atendiam a critérios estabelecidos pelas próprias participantes, passou-se a negociar diretamente com as suas respectivas direções a realização de Encontros em que tal proposta seria apresentada e discutida. Nesses Encontros ${ }^{[9]}$, que eram realizados em um único dia, se apresentava a proposta e o desenvolvimento do Programa de Formação, e ao final, colocava-se em discussão a implementação do Observatório, ressaltando-se que para tal tornava-se indispensável a mobilização das próprias trabalhadoras.

Ao longo dos debates que ocorreram, a proposta de constituição de Comissões de Saúde era colocada pelo grupo de pesquisadores profissionais, com a sugestão de que deveriam ser formadas por trabalhadoras de diferentes segmentos profissionais. As Comissões se constituíram a partir da autoindicação, ou de nomes apontados por colegas, que eram consensualmente referendados pelo conjunto de trabalhadoras presentes, legitimando-as. A expectativa era de que elas se responsabilizassem pela vigilância das situações de trabalho potencialmente geradoras de agravos, visando a 
promoção da saúde a partir das situações de trabalho (Silva et al., 2009). O Observatório ganhou contornos mais visíveis em cada escola na medida em que avançavam, concomitantemente à atuação das Comissões de Saúde e os estudos realizados por pesquisadores e trabalhadoras - que participavam ou não dessas Comissões - acerca das atividades ali executadas, com foco principal nas condições de saúde, sempre pautadas por uma perspectiva de compreender $\leftrightarrow$ transformar as situações de trabalho. Após selecionar os setores da escola a serem gradativamente objeto de investigação, organizava-se uma visita de membros da Comissão, em conjunto com integrantes da equipe de formação, para dar início ao levantamento de aspectos específicos comprometedores (bem como favorecedores) da saúde das trabalhadoras.

No primeiro contato com as trabalhadoras de cada setor, apresentava-se como o monitoramento seria efetivado. Com o intuito de ampliar a CAPI, retomavam-se os objetivos do Programa de Formação, as etapas já realizadas, e a multiplicadora de cada escola participante falava sobre o processo vivenciado. Simultaneamente fez-se uso de técnicas de observação global e sistemática, inspiradas no método de análise da Ergonomia da Atividade (Guérin et al., 2001), das diversas situações de trabalho desenvolvidas nas escolas. Estas foram realizadas por auxiliares de pesquisa (alunos de graduação e pós-graduação), cujos materiais gerados eram sistematizados inicialmente para serem submetidos à discussão e validação pelas trabalhadoras das escolas.

21 As observações globais possibilitaram uma importante aproximação e compreensão da complexidade concernente às atividades em questão. Elas eram realizadas em momentos diferenciados, com o objetivo de se identificarem os acontecimentos envolvidos no dia a dia das trabalhadoras. Já as observações sistemáticas se desenrolavam de forma mais rigorosa e exaustiva, na medida em que se buscava apreender detalhadamente os movimentos, gestos, posturas, atentando para os recursos cognitivos requeridos pelas atividades, como por exemplo as trocas de informações e verbalizações realizadas nos coletivos de trabalho. Também apontavam indicadores acerca das estratégias usadas pelas trabalhadoras na regulação das atividades e na promoção de sua saúde. Utilizou-se ainda a técnica de mapeamento dos fatores de risco (inspirada em Oddone et al., 1986), ferramenta que expressa a reunião de dados vinculados à presença, nos ambientes de trabalho, de fatores potencialmente danosos à saúde, cujas informações levantadas devem ser validadas coletivamente. As discussões em grupo abriam espaço para que as pessoas refletissem sobre o seu trabalho e o das outras trabalhadoras.

Para viabilizar o mapeamento, construiu-se, juntamente com as trabalhadoras, um quadro das atividades de trabalho na escola, com o objetivo de realçar, com base na indicação das próprias trabalhadoras, os riscos presentes em cada uma delas. Ao final, apontavam-se as recomendações de mudanças. Esse material, sistematizado e analisado, gerou relatórios que depois de submetidos à avaliação e validação das trabalhadoras foram entregues para as direções das escolas, visando a transformação local das condições e formas de organização do trabalho, ou então, para que se conduzisse, em parceria com o sindicato, alterações de caráter mais geral à Secretaria de Educação ou a outros órgãos públicos pertinentes.

Embora as Comissões de Saúde somente se reunissem com a presença dos pesquisadores profissionais, foi profícua a produção de materiais acerca das situações de trabalho. Além de outros efeitos - frutos dos diálogos e debates travados nas comissões, bem como nas diferentes etapas e ciclos do Programa de Formação -, pode ser registrado que 
as merendeiras de uma das escolas reivindicaram sua participação nas reuniões pedagógicas, na medida em que elas entendiam que também poderiam contribuir para a discussão das questões que atravessavam as unidades escolares.

Enfim, é importante sinalizar que o caráter de pesquisa-formação-intervenção possibilitou, ao longo do desenvolvimento do Programa, a realização de diversas mudanças das condições e formas de organização do trabalho. o levantamento de determinadas problemáticas possibilitou às trabalhadoras discutirem entre elas e com as direções de cada uma das escolas formas de enfrentar e resolver os problemas encontrados. Assim, o movimento contínuo de pesquisa-formação-intervenção (ver Figura 2), agenciado por CAPI, apresentou-se um dispositivo importante na luta das trabalhadoras de escolas em João Pessoa, na medida em que se mostrou fecundo como instrumento de compreensão $\leftrightarrow$ transformação do que se apresentava nocivo para a vida e a saúde nos ambientes de trabalho.

Figura 2: Operacionalização do Programa de Formação em Saúde, Gênero e Trabalho nas Escolas em João Pessoa

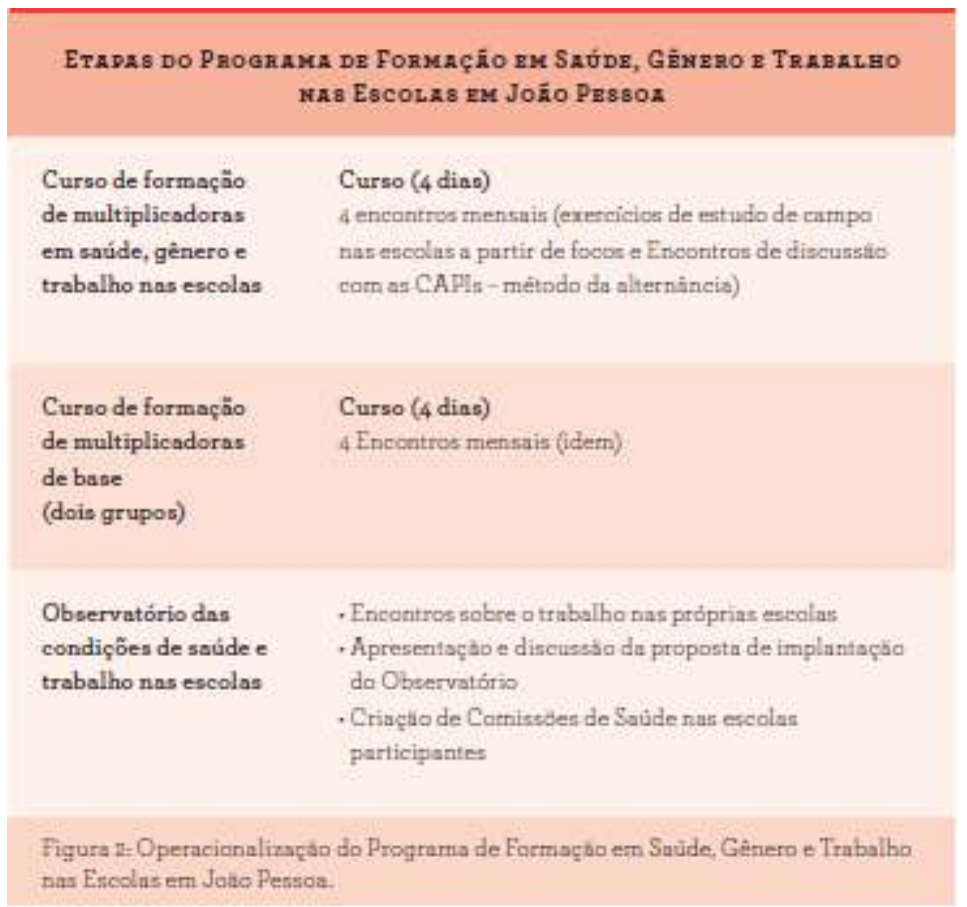

\section{Desafios e potencialidades do Programa de Formação}

Ao longo da realização do Programa foi se constituindo um processo contínuo e permanente de avaliação das suas várias etapas e ciclos, envolvendo trabalhadoras e investigadores profissionais, que favoreceu uma frequente regulação das estratégias de condução das atividades formativas, de pesquisa e intervenção nas escolas na cidade de João Pessoa. Essa dinâmica nos permite indicar, a seguir, alguns dos avanços e potencialidades que entendemos ter sido gestados no sentido de ampliar a capacidade de ação das trabalhadoras, bem como algumas das dificuldades, entraves, empecilhos e desafios vivenciados. O Programa, conforme realizado em João Pessoa, foi fruto de uma 
parceria que gradativamente foi sendo construída entre investigadores profissionais, militantes sindicais e trabalhadoras de escola. Ou seja, cabe aqui ressaltar que pensamos ser possível intervir-investigar, mesmo quando demandas explícitas desse tipo não se apresentam. Em nossas experimentações, em alguns casos, o Sindicato atuou como mediador da demanda, como se deu no estado do Rio de Janeiro. Em outros, como em João Pessoa, essa demanda foi construída conjuntamente por investigadores profissionais e trabalhadoras, tomando os primeiros a iniciativa - já que os problemas sociais subjacentes a elas dão suporte a essa produção. Entendemos que a forma organizativa Sindicato pode ou não ser a mais pertinente para sua emergência (Silva \& Athayde, 2001.

Não obstante as dificuldades e os desafios que serão assinalados a seguir, vários aspectos quanto à aceitação, implantação e desenvolvimento do Programa - visando à construção de um Observatório contínuo e permanente das condições e formas de organização do trabalho e saúde - apontam para a potência dessa experimentação. Lembremos que a realização de tal proposição foi posta em discussão pelo Sindicato (Sintem-JP) em um congresso dos trabalhadores na educação realizado na cidade de João Pessoa, sendo unânime sua aprovação.

Acreditamos que os resultados positivos alcançados devem-se especialmente ao método e aos procedimentos previstos - envolvendo sistematicamente a alternância entre estudos nos locais de trabalho e Encontros das Comunidades Ampliadas de Pesquisa para discussão. Essa alternância mostr ou-se bastante fecunda, pois possibilitou maior compreensão do trabalho e viabilizou o encaminhamento de ações de naturezas diversas, que envolveram mudanças concretas nas condições e na organização do trabalho, nas formas de luta pela saúde e mesmo transformações nos modos de perceber e sentir o trabalho (de si e do outro), as relações sociais de gênero, a saúde e a vida.

O Programa de Formação, sob a ótica das relações sociais de gênero, procurou problematizar a construção histórica das práticas sociais de homens e mulheres frente à divisão social do trabalho (Hirata, 2002; Kergoat, 2010). Ao longo dos Encontros das CAPIs, percebemos que uma parcela das trabalhadoras foi, num processo sutil e dinâmico, descontruindo as formas hegemônicas de percepção das relações sociais de gênero, a partir da desnaturalização dos papéis socialmente atribuídos aos homens e às mulheres. Nessa direção, passou-se a questionar a representação veiculada, por parte da sociedade e, até então, assumida por elas próprias, das escolas - principalmente das primeiras séries do ensino fundamental - como um local de trabalho de mulheres, já que as escolas eram vistas como uma extensão do trabalho doméstico, do cuidado com as crianças. Este processo contribuiu, por exemplo, para a ocupação maciça e gradativamente do magistério das séries iniciais por representantes do sexo feminino nas escolas brasileiras, bem como para um modo específico de exercer a docência. Da mesma forma, questionou-se também o fato dos poucos homens professores existentes nessas escolas, ocuparem na maioria das vezes o cargo de direção, e no caso dos funcionários exercerem as funções de portaria e vigilância, enquanto as mulheres (funcionárias) assumiam as tarefas relativas à confecção de alimentos e serviços gerais. Entretanto, tais questionamentos não impediam que em outros momentos as trabalhadoras identificassem a reprodução da perspectiva naturalizante das relações entre os sexos nas interações diferenciadas que estabeleciam com seus alunos e alunas. 
29 A experimentação do Programa possibilitou também, em vários momentos, que algo enunciado trouxesse à tona uma situação de trabalho desagradável que não se desejava relembrar, que se queria até mesmo esquecer. Dejours $(1997,2004,2012)$ nos alerta para a existência dos sistemas defensivos (de tipo estratégico ou ideológico) criados pelos trabalhadores para lidar com o sofrimento gerado no/do trabalho. Nessa direção, Cru e Dejours (1987) salientam que não se deve ir contra essas defesas, por exemplo, investindo em campanhas de segurança que ressaltem de modo repetido os riscos presentes nos locais de trabalho, que por sua vez seriam potencialmente geradores de medo. Ambos afirmam que tais defesas se manifestam, dentre outras formas, por intermédio do desafio e da ludicidade diante dessas situações, permitindo aos trabalhadores adotar uma postura menos passiva em relação ao trabalho. Para eles é fundamental construir dispositivos que mobilizem a criação, a engenhosidade, o bom humor, o desafio, as possibilidades de transformação, evitando o aprisionamento engendrado pelo recorrente alerta dos riscos e dos sofrimentos vivenciados no trabalho, que tende a minar a atuação das defesas, sem apresentar alternativas efetivas de enfrentamento. Como diria Schwartz (2010), é preciso que estejamos atentos às reservas de alternativas presentes na atividade, já que estas são pistas para a construção de uma vida em comum de melhor qualidade.

30 Nessa direção, vale destacar inicialmente o modo de se encaminhar a luta pela gestão do espaço de trabalho. Durante o primeiro ano do processo de formação, muitas escolas passavam por reformas no seu arranjo arquitetônico, que estavam sendo criticadas por serem feitas sem considerar a participação das trabalhadoras que ali desenvolvem suas atividades. Após o seu engajamento no Programa, relataram ter procurado conversar com os engenheiros responsáveis pelas obras, pressionando-os para que incluíssem suas sugestões de intervenções mais adequadas aos espaços escolares.

31 Outras mudanças também foram implementadas em várias das escolas, tais como: a divisão de horários do recreio por faixa etária dos alunos; a substituição dos quadro negros por quadros brancos nas salas de aulas; a retirada dos botijões de gás de dentro das cozinhas; a colocação de rodinhas no fogão, para possibilitar seu deslocamento até à bancada onde se serviam as refeições aos alunos, evitando o manuseio e transporte de panelas pesadas pelas merendeiras; e a diminuição da altura dos fogões, em algumas destas escolas, para torná-los mais adequad os e menos prejudicia is à saúde das merendeiras.

32 Ao longo do processo foi fundamental observar como os estabelecimentos escolares, submetidos às mesmas diretrizes da Secretaria Municipal de Educação, apresentavam modos diferentes de gerenciamento do trabalho. Enquanto alguns registravam conflitos mais acirrados entre as diversas categorias profissionais, em outros se constatava a presença de relações de cooperação, com melhores resultados na qualidade do ensino e com implicações favoráveis à saúde das trabalhadoras. Da mesma forma, verificou-se que se em determinadas escolas algumas trabalhadoras desenvolviam astuciosamente formas diferentes de lidar com certas prescrições administrativas, em outras se submetiam com maior frequência à rigidez de tais prescrições. Perceber a possibilidade do desenvolvimento de estratégias diferentes de regulação do trabalho permitia discutir a cena do trabalho como fruto não apenas de uma imposição da Secretaria, mas também da gestão coletiva empreendida pelas próprias trabalhadoras (Schwartz, 2010). Por intermédio do Programa de Formação inverteu-se, portanto, a lógica mais frequentemente utilizada nos estudos e intervenções acerca da relação saúde-trabalho, 
privilegiando-se, como aponta Dejours (2004), não somente o sofrimento patogênico, os processos de adoecimento, mas simultaneamente as descobertas que conduzem à conquista da saúde e à manutenção no campo da normalidade.

Ou seja, quando se discutiam as condições e formas de organização do trabalho nas escolas, foi muito importante não apenas focar os riscos à saúde, mas também observar que "trabalhar é gerir" (Schwartz, 2010), podendo se configurar nesse movimento a melhoria da vida em comum. Desse modo, uma escola que, mesmo estando em condições mais satisfatórias que outras, tenderia a não se estagnar, já que o objetivo não deveria se restringir apenas a corrigir problemas, mas a melhorar continuamente os meios e modos de trabalho, em uma perspectiva de promoção da saúde a partir das situações de trabalho. Assim, como Canguilhem $(1995,2001)$, pensamos que saúde tem a ver com a capacidade de o ser vivo estabelecer novas normas de vida, tolerar e enfrentar as infidelidades e as agressões do meio - o que significa mais do que adaptarse (Brito \& Athayde, 2003; Neves, Seligmann-Silva \& Athayde, 2004). Nesse sentido, falar sobre saúde é discorrer sobre um cotidiano que demanda ininterrupta mobilização da subjetividade (Dejours, 2004), ou do corpo-si, como propõe Schwartz (2000b).

Outro resultado importante foi que na trama do dispositivo CAPI se teceu um tipo de sociabilidade que reuniu horizontalmente diferentes profissionais de escola, sem desconsiderar suas diferenças - professoras, merendeiras/cozinheiras, auxiliares de serviço, técnicas, diretoras etc. -, todas compartilhando o mesmo espaço, tendo acesso às mesmas informações, realizando conjuntamente os exercícios de estudo de campo, enfim, dialogando-confrontando suas experiências. Esse compartilhamento evidenciou a diversidade de opiniões, olhares, concepções acerca de questões e problemas que envolvem o trabalho escolar, a saúde e as relações de gênero, possibilitando sua desnaturalização.

Nessa direção, entendemos que o dispositivo CAPI favoreceu a constituição de um espaço de experimentação para a igualdade na diferença, na busca da compreensão e transformação dos locais de trabalho. De fato, desde o momento em que o Programa foi concebido, tinha-se o propósito de intervir no conjunto de situações de trabalho, pois avaliava-se que uma proposta dirigida a um segmento profissional isolado seria artificial. Em primeiro lugar, porque percebia-se que no coletivo de trabalho da escola a atividade de trabalho de cada coletivo profissional específico está em relação com as atividades dos demais e é influenciada por elas - desse modo, a interlocução entre diferentes coletivos profissionais seria algo positivo no processo de formaçãoinvestigação-intervenção. Em segundo lugar, porque pesquisas anteriores já indicavam a separação existente entre trabalhadoras docentes e não docentes, expressa em desconhecimento e não prática de solidariedade entre as diferentes categorias profissionais, o que deveria ser urgentemente enfrentado. Para tanto, o processo de formação proposto já se apresentava como uma estratégia de se exercitar quebrar os muros invisíveis da escola (Brito \& Athayde; 2003; Silva et al., 2009).

o compartilhamento das histórias de trabalho enriqueceu as discussões, ao mesmo tempo que trouxe novos desafios, novos problemas a desvendar. A experiência de cada uma fortaleceu a compreensão das trabalhadoras sobre o que estava acontecendo nas escolas e gerou vários tipos de alianças que foram eficazes nas transformações das situações de trabalho. Isso permitiu a condução de projetos de intervenção contemplando o conjunto de profissionais da escola, envolvendo-as nos processos de mudança no trabalho umas das outras, posto que as discussões eram feitas de modo 
coletivo. Dessa forma, a multiprofissionalidade presente nas escolas, que fazia parte da composição dos grupos de trabalhadoras que integraram essa experimentação, não foi pensada como um mero somatório de pessoas, mas como uma maquinação dialógica, de confrontações, em que profissionais de diversos níveis e funções eram questionadas, contestadas, entravam em desacordo, se harmonizavam (Silva, 2003). O que era dito por algumas acerca da sua atividade descortinava para outras o que sempre se naturalizou ou se subestimou.

37 É importante reforçar que cada uma se expressava de acordo com o seu repertório de linguagem e o ponto de vista de sua atividade. Como, por exemplo, quando uma merendeira, para falar sobre as pressões e a sobrecarga no/do trabalho apresentou um cartaz com o desenho de um grande botijão de gás prestes a explodir, expressando em uma imagem muito mais do que as palavras poderiam exprimir. Outro episódio importante foi quando em um dos Encontros da CAPI debateu-se acerca da relação das merendeiras/cozinheiras com o funcionário da portaria que é responsável pelo controle da entrada e saída de pessoas na escola. Aquelas criticavam o fato do porteiro não aceitar se ausentar do seu posto de trabalho e deixar outra pessoa no seu lugar para ajudá-las na cozinha. Entretanto, o mesmo procurava explicar para elas que não era qualquer um que poderia ficar no seu lugar, porque se o trabalho dele poderia ser visto como algo aparentemente simples, em alguns momentos, como por exemplo, quando surgisse um imprevisto do ponto de vista da segurança, somente ele estava treinado para se antecipar e regular tal incidente. $O$ diálogo estabelecido entre eles exigiu deste trabalhador uma explicitação mais clara de sua atividade, o que permitiu que as merendeiras percebessem que não era uma questão de má vontade, mas sim uma exigência da atividade do porteiro que elas desconheciam.

De um modo geral, as diretoras presentes nos Encontros procuravam ajudar as funcionárias de serviços gerais, confecção de alimentos, etc., que exerciam suas atividades nas mesmas escolas nas quais aquelas estavam lotadas, a desenvolverem os trabalhos de campo propostos pelo Programa de Formação. Mesmo considerando a existência de momentos de discordâncias entre trabalhadoras de distintas categorias profissionais, com níveis diferentes de escolarização, várias das funcionárias apontavam para a importância das parcerias com outros tipos de profissionais, já que todas participavam do Programa "em pé de igualdade". Ao longo do processo, as trabalhadoras aprenderam a escutar e respeitar o ponto de vista das diferentes colegas em face do objetivo de comprender $\leftrightarrow$ transformar as situações de trabalho.

Uma outra situação de mudança pode ser ainda visualizada na autocrítica pública realizada pelo então presidente do Sindicato em uma atividade promovida a partir do Programa de Formação, ao recordar que quando a equipe de investigadores profissionais propôs a realização do Programa, ele sugeriu que o primeiro grupo de multiplicadoras fosse composto somente de professoras, já que estas teriam mais condições de participar de um Programa com essas características. O mesmo lembrou que a equipe o convenceu de que era importante a participação de outras trabalhadoras não docentes desde o início. Todavia, posteriormente, em sua avaliação, foram exatamente essas trabalhadoras que mais contribuíram para o sucesso do Programa.

Vimos que as parcerias entre trabalhadoras de uma mesma escola ou de escolas diferentes, bem como o apoio da equipe de pesquisadores profissionais, principalmente durante os exercícios de campo nas escolas, foram fundamentais para garantir os resultados positivos do Programa - o que nos leva a pensar o dispositivo CAPI como 
uma zona de desenvolvimento proximal, conforme assinalado por Vigotski (1984). Este percebeu que crianças (especialmente aquelas com deficiências) em contato com outras mais experientes ou com adultos resolviam problemas que sozinhas não conseguiriam. Daí sinalizar a importância da interação entre crianças com idades e experiências diferentes e do auxílio dos adultos na formação delas, já que tal encontro mobilizaria processos de desenvolvimento, na medida em que essas crianças conseguiam realizar tarefas que somente seriam capazes de fazê-las sem apoio mais tarde.

Clot (2006) procurando ampliar tal conceito, propôs o de zona de desenvolvimento potencial, em que os trabalhadores poderiam expandir o seu poder de agir a partir de uma atividade coletiva de discussão acerca de suas atividades. 0 referido autor, numa perspectiva desenvolvimental inspirada em Vigotski (1984) e atento à importância da construção de dispositivos dialógicos, ao corroborar a dificuldade de se acessar o ponto de vista da atividade por intermédio dos métodos diretos, sinaliza a importância da construção de métodos indiretos que propiciem ao trabalhador viver uma experiência produtora de outras experiências (Clot, 2006, 2010). Ainda apoiando-se em Vigotski, afirma que para estudar o desenvolvimento faz-se necessário produzi-lo durante a realização da própria pesquisa. Para tanto, propõe que sejam elaborados instrumentos de ação que possibilitem aos trabalhadores desenvolverem a sua experiência, produzindo uma zona de desenvolvimento potencial. Porém, instaurar esse dispositivo só é possível se considerarmos o esforço de colaboração no sentido de se fazer entender, de colocar em diálogo diferentes profissionalidades, formas de raciocínio, linguagens, constituindo, assim, uma Comunidade Dialógica de Pesquisa (França, 2007) que segue as diretrizes de Bakthin (2003), Faïta (2005) e Clot (2006), na medida em que estes apontam para o valor da experiência da atividade linguageira na produção de outras experiências.

Da mesma forma, percebemos nos Encontros das CAPIs que o trabalho em comum realizado por trabalhadoras adultas, que possuíam diferentes competências, favorecia o seu desenvolvimento - tanto das que precisavam de apoio nas tarefas de escrita e sistematização da experiência, como daquelas que passaram a compreender um dado contexto que lhes era desconhecido, como é o caso de algumas professoras que até então sinalizavam não saber da importância do trabalho educativo realizado pelas merendeiras e da possibilidade deste de expô-las a processos de sofrimento patogênico e adoecimento (Brito \& Athayde, 2003; França et al, 2013). Verificamos também que durante as alternâncias, principalmente em relação aos exercícios de estudo de campo, cada CAPI foi se expandindo de diferentes formas, a partir das alianças e parcerias que as trabalhadoras estabeleceram nos locais de trabalho. Muitas delas, que se engajaram precocemente ${ }^{[10]}$ na CAPI, participaram posteriormente do Programa (momento de formação das multiplicadoras de base), dando continuidade ao processo de formação de forma mais sistemática e formal. Tivemos ainda a satisfação de observar a demanda crescente em relação ao tipo dessa proposta, tanto em João Pessoa como no estado do Rio de Janeiro, o que sinaliza para o seu impacto positivo. Verificamos também a formulação desse tipo de demanda em outras regiões do Brasil, seja em outros estados do sudeste (Espírito Santo), seja no norte (Amazonas e Tocantins). Buscando dar conta desta potência em rede e desenvolvê-la, em 2011 foi criado o site "Encontros sobre a vida, a saúde e o trabalho nas escolas públicas"[11]. Buscou-se contribuir para a continuidade das transformações geradas ao longo desse processo e para a reflexão permanente das trabalhadoras que participaram do Programa de Formação, assim fortalecendo as CAPIs, além de propiciar maior difusão de saberes e a produção de 
novos conhecimentos acerca das relações entre o trabalho e a saúde de trabalhadoras de escolas públicas (Brito et al., 2012).

Em relação a outros desafios, destacamos, no entanto, que uma parcela das trabalhadoras teve dificuldades para realizar os exercícios de campo ou os relatórios durante a fase das alternâncias, assim como não se engajou efetivamente na implantação do Observatório permanente das condições de trabalho e saúde e na constituição das Comissões de Saúde nas escolas. O principal motivo relatado era a falta de tempo devido à sobrecarga de trabalho. No caso da dificuldade de elaboração dos relatórios, acreditamos que isso se deu principalmente em razão do predomínio da cultura oral na realidade brasileira e, em certos casos, do baixo nível de escolaridade de algumas trabalhadoras não docentes. Vimos, porém, que essas dificuldades puderam ser superadas em diversos momentos, por meio da criação de laços de cooperação com colegas da escola que tinham mais facilidade para registrar e relatar os procedimentos adotados, os materiais gerados e as possíveis mudanças efetivadas.

Outra dificuldade concerne à não devida compreensão, por parte das trabalhadoras, dos papéis específicos que estas e investigadores profissionais ocupavam no processo em curso. Em algumas escolas, na maioria das vezes, as trabalhadoras ficavam na dependência de tomadas de iniciativa por parte dos auxiliares de pesquisa, em vez de tê-los apenas como apoio. Acreditamos que o lugar dos investigadores profissionais precisa ser mais bem explicitado e que estes podem e devem assumir um papel ativo (o que não significa pleno protagonismo, menos ainda direção) nas práticas de formaçãopesquisa-intervenção, auxiliando os coletivos de trabalhadores e trabalhadoras na elaboração de suas estratégias de ação. Ou seja, não se trata de fazer pelas trabalhadoras de escolas, mas com elas, tendo em vista que o grande desafio é poder exercitar algumas ações coletivas comuns.

Diferentemente do que imaginávamos em um primeiro momento, as trabalhadoras que participaram dessa experimentação também não se sentiam em condições de assumir sozinhas, nem em duplas, a fase de multiplicação prevista pelo Programa de Formação. Diziam que esta fase era delicada e que ainda precisavam do apoio mais efetivo da equipe de pesquisadores até que acumulassem mais experiência. Tais dificuldades, a nosso ver, sinalizam para a necessidade da criação de estratégias que viabilizem o desenvolvimento das diversas etapas previstas, como: favorecer ou fortalecer ainda mais as relações de cooperação entre as participantes; propiciar maior envolvimento das multiplicadoras no momento da formação das trabalhadoras de base; e garantir um acompanhamento, ao menos inicial, mais amiúde por parte da equipe de investigadores profissionais na elaboração dos exercícios desenvolvidos pelas trabalhadoras.

Durrive (2010) sinaliza que colocar em palavras a experiência é sempre um desafio que exige auxílio de outros colegas e dos profissionais de pesquisa-intervenção. Isso porque os códigos da linguagem verbal e escrita não dão conta de expressar as dimensões sensoriais e afetivas da atividade, além de que falar sobre esta significa correr riscos de assumir coletivamente as escolhas e decisões, muitas vezes polêmicas, que vêm sendo $\operatorname{adotadas}^{[12]}$. Dejours (2004), por sua vez, aponta para o risco de o trabalhador, ao expressar seu desagrado com uma situação de trabalho, deparar-se com o próprio sofrimento. Assim, dispositivos como o aqui em foco exige um compromisso ético, a construção de relações de confiança entre parceiros de trabalho - não sendo, portanto, um trabalho de fácil realização e encaminhamento, visto que a burocratização dessas relações é um risco permanente, o qual deve ser objeto de discussão sistemática. 
47 No que concerne mais especificamente à experiência de implantação e desenvolvimento do Observatório, alguns desafios e dificuldades também foram apontados e discutidos nos encontros de avaliação que previam a participação de todas as integrantes das Comissões de Saúde e representantes da direção do sindicato. A participação nem sempre assídua das multiplicadoras e, principalmente, a não efetiva mobilização das Comissões apresentaram-se como grandes empecilhos para que o Observatório se consolidasse em cada local de trabalho. Segundo relatos das próprias trabalhadoras, os motivos para o não engajamento nessa etapa do processo de formação foram as aposentadorias de algumas trabalhadoras-multiplicadoras, as transferências de escola, os adoecimentos e, fundamentalmente, a sobrecarga de trabalho, comprometendo sua disponibilidade. Reiterava-se que se o Programa estivesse associado ao próprio projeto político pedagógico e, por conseguinte, ao planejamento das escolas, ele teria um efeito mais duradouro e a implicação das trabalhadoras seria maior. Pensamos que as diversas formas de precarização do trabalho, com a sobrecarga e o número insuficiente de trabalhadoras nas escolas, apresentam-se como fatores que exigem novas estratégias de formação e intervenção, uma vez que a efetivação e a manutenção das Comissões de Saúde mostraram-se muito difíceis. Some-se a isto a possível presença de sistemas defensivos de tipo ideológico (Dejours, 2004, 2012), que podem afastar as trabalhadoras do debate em torno dos riscos no/do trabalho, distanciando-as assim da participação em dispositivos que as façam refletir coletivamente acerca da realidade na qual se inserem e das implicações desta na sua saúde. Tal discussão remete (ao menos no caso do Brasil) ao principal desafio a ser enfrentado e respondido em cada intervenção: como contribuir efetivamente para a construção e a manutenção de práticas de formação em contextos de precarização do trabalho?

Por fim, um problema adicional foi a oscilação de engajamento do Sindicato. Por diversas vezes foi solicitado pelas trabalhadoras e investigadores profissionais o agendamento, sem êxito, de reuniões com a sua direção para discutir os encaminhamentos do Programa de Formação, bem como realizar uma avaliação do processo de implantação do Observatório nas escolas. Reflexões anteriores por nós elaboradas já abordavam a ausência da participação dos sindicatos dos trabalhadores em educação na institucionalização e no desenvolvimento de ações em Saúde do Trabalhador na Paraíba (Silva \& Athayde, 2001). Embora a direção do Sintem tenha apoiado e participado de modo mais efetivo quando das primeiras etapas (curso e alternâncias) do processo de formação das multiplicadoras, não obstante membros da sua diretoria terem participado das discussões relativas à Rede Nacional de Atenção Integral à Saúde do Trabalhador (Renast) no estado da Paraíba e até mesmo constituído em sua estrutura sindical um coletivo responsável pelas questões de saúde, gênero e etnia, seu engajamento deu-se apenas parcialmente nas ações do Observatório, não considerando essa fase do Programa como um trabalho de base a ser efetivamente assumido pelo Sindicato. As trabalhadoras-multiplicadoras que fizeram parte dos Encontros de avaliação queixaram-se da sua ausência, enfatizando a necessidade de retomar a participação do Sindicato no Programa, já que as mudanças mais importantes ocorridas nas escolas, ao longo desse processo, foram implementadas quando o Sindicato se fazia presente. Porém, torna-se necessário estarmos atentos às lutas desenvolvidas pelas trabalhadoras, mesmo sem o auxílio do Sindicato e o fortalecimento dessas estratégias alternativas, para que o movimento de transformação não fique limitado às possibilidades do dispositivo sindical. 


\section{Considerações finais}

Entendemos que uma prática compreensivo $\leftrightarrow$ transformadora só é possível na medida em que se disponha de instrumentos conceituais e metodológicos para sobre ela refletir. Com o Programa de Formação em Saúde, Gênero e Trabalho nas Escolas, buscamos implementar a articulação crítico-criativa entre o saber advindo da experiência de vida/trabalho/saúde das trabalhadoras e o conhecimento científico que como investigadores profissionais temos como patrimônios e estamos produzindo, no horizonte de uma sinergia renovadora desse conhecimento e dessa experiência. Acreditávamos, portanto, que a sinergia entre esses dois polos não envolvia a crítica apenas do conhecimento científico, mas também da experiência do trabalho (a forma como era vivida pelas trabalhadoras e as suas implicações no processo de subjetivação e saúde/doença), contribuindo para o processo de reformulação e produção de novos saberes, permitindo que novas formas de diálogo acerca das questões ligadas à saúde no trabalho sejam desenvolvidas.

Ao definir esse Programa como um dispositivo de formação $\leftrightarrow$ pesquisa $\leftrightarrow$ intervenção $\mathrm{em}$ rede, sinalizávamos para que com o seu desenvolvimento e a sua progressão por meio da multiplicação se constituíssem redes de trabalhadoras interessadas e mais bem preparadas para compreender $\leftrightarrow$ transformar os processos e as relações sociais de trabalho. Multiplicar, na concepção desse Programa, não significava reproduzir exata e mecanicamente o modelo proposto. Mesmo respeitando os procedimentos metodológicos que estavam fundamentados teoricamente e já tinham sido testados, era fundamental que as trabalhadoras-multiplicadoras fossem capazes de recriar e readaptar o método segundo as diferentes realidades, e cada meio específico. Vê-se claramente que propostas de experimentação nessa linha, visando a transformação das situações deletérias à saúde e a promoção da saúde, requer tempo necessário à sua realização, bem como alto grau de persistência e paciência. Do nosso ponto de vista, a constituição de Comunidades Ampliadas de Pesquisa e Intervenção indica potencialidades e desafios para se avançar na perspectiva de compreender $\leftrightarrow$ transformar a partir das situações de trabalho. Se várias mudanças foram implementadas, acreditamos que muitas ainda poderão se concretizar a partir da consolidação de proposições como as desenvolvidas no curso do Programa, e da problematização e amadurecimento de ideias que foram assinaladas ao longo desse processo.

\section{BIBLIOGRAFIA}

Athayde, M., Zambroni-de-Souza, P., \& Brito, J., (2014). Intervenção e pesquisa em Psicologia: uma postura ergológica. In Bendassolli, P., \& Soboll, L., A. (Orgs.). Métodos de pesquisa e intervenção em Psicologia do Trabalho. Clínicas do Trabalho (pp. 129-157). São Paulo: Editora Atlas. 
Brito, J. (2004). Saúde do trabalhador: reflexões a partir da abordagem ergológica. In Figueiredo, M. Athayde, M., Brito, J., \& Alvarez, D. (Orgs.), Labirintos do trabalho: interrogações e olhares sobre o trabalho vivo (pp. 91-114). Rio de Janeiro: DP\&A Editora (Espaços do Desenvolvimento).

Brito, J. \& Athayde, M. (2003). Trabalho, educação e saúde: o ponto de vista enigmático da atividade. Revista Trabalho, Educação e Saúde, 1(2): 63-89.

Brito, J., Athayde, M., \& Neves, M. Y. (Orgs.). (2003a). Cadernos de método e procedimentos. Programa de Formação em Saúde, Gênero e Trabalho nas Escolas. João Pessoa: Editora Universitária UFPB.

Brito, J., Athayde, M., \& Neves, M. Y. (Orgs.). (2003b). Cadernos de textos. Programa de Formação em Saúde, Gênero e Trabalho nas Escolas. João Pessoa: Editora Universitária UFPB.

Brito, J., Athayde, M., Neves, M. Y., Muniz, H., Pina, J. A., Souza, K. R., \& Santos, M. B. (Orgs.). (2003c). Cadernos de Relatos de Experiências. Programa de Formação em Saúde, Gênero e Trabalho nas Escolas. João Pessoa: Editora Universitária UFPB.

Brito, J., Neves, M. Y., Hyppolito, A., Alvarez, D., Silva, E., Muniz, H., Souza, K., França, M., \& Athayde, M. (2012). The use of a website as an interaction and training device in health, gender and work in schools. Work (Reading, MA), 41, 4.661-4.668.

Canguilhem, G. (1995). O normal e o patológico. Rio de Janeiro: Forense Universitária.

Canguilhem, G. (2001). Meio e normas do homem no ambiente de trabalho. Proposições, 12(2-3), 109-121.

Clot, Y. (2006). A função psicológica do trabalho. Petrópolis: Vozes.

Clot, Y. (2010). Trabalho e poder de agir. Belo Horizonte: Fabrefactum.

Costa, J. D. (2004). 0 "Programa de Formação em Saúde, Gênero e Trabalho em Escolas Públicas" e a produção de subjetividades. Dissertação (Mestrado) - Programa de Pós-Graduação em Psicologia Social, Universidade Federal da Paraíba, João Pessoa.

Cru, D.; \& Dejours, C. (1987). Saberes de prudência nas profissões da construção civil: nova contribuição da Psicopatologia do Trabalho à análise da prevenção de acidentes na construção civil. Revista Brasileira de Saúde Ocupacional, 15(59), 30-34.

Dejours, C. (1997). O fator humano. Rio de Janeiro: Editora da FGV.

Dejours, C. (2004). Trabalho, subjetividade e ação. Revista Produção, 14(3), 27-34.

Dejours, C. (2012). Trabalho Vivo. Sexualidade e trabalho. v.1. Brasília: Paralelo 15.

Durrive, L. (2007/2010) O formador ergológico ou ergoformador: uma introdução à ergoformação. In Schwartz, Y., \& Durrive, L. (Orgs.), Trabalho e ergologia: conversas sobre a atividade humana (pp. 295-307). $2^{\text {a }}$ ed. Niterói: Eduff.

Faïta, D. (2005). Análise dialógica da atividade profissional. Rio de Janeiro: Imprinta.

França, M. B. (2007). Uma comunidade dialógica de pesquisa: atividade e discurso em guichê hospitalar. São Paulo: Fapesp/Educ.

França, M., Athayde, M., Muniz, H., Neves, M., \& Brito, J. (2013). Clínica do trabalho e experiência de formação com trabalhadoras de escolas públicas no Brasil. Cadernos de Psicologia Social e do Trabalho, 16, 69-89.

Freire, P. (1967/1983). Educação como prática de liberdade. 14ª ed. Rio de Janeiro: Paz e Terra.

Freire, P. (1970/1987) Pedagogia do oprimido, 17ª ed. Rio de Janeiro: Paz e Terra. 
Freire, P. (1996). Pedagogia da autonomia: saberes necessários à prática educativa. Rio de Janeiro: Paz e Terra.

Freire, P., \& Faundez, A. (2002). Por uma pedagogia da pergunta. $5^{\text {a }}$ ed. Rio de Janeiro: Paz e Terra. Guérin, F., Laville, A., Daniellou, F., Duraffourg, J., \& Kerguelen, A. (2001). Compreender o trabalho para transformá-lo: a prática da ergonomia. São Paulo: Edgard Blucher.

Hirata, H. (1993). Paradigmes du travail, un “point de vue transversal”. Futur Antérieur,16, 5-10.

Hirata, H. (2002). Nova divisão sexual do trabalho? Um olhar voltado para a empresa e a sociedade. São Paulo: Boitempo.

Kergoat, D. (2010). Dinâmica e consubstancialidade das relações sociais. Novos Estudos CEBRAP, 86, 03-103.

Merhan, F., Ronveaux, C., Vanhuille, S. (Dirs.) (2007). Alternances en formation. Bruxelles: De Boeck \& Larcier.

Muniz, H.P., Brito, J., Souza, K. R., Athayde, M., \& Lacomblez, M. (2013). Ivar Oddone e sua contribuição para o campo da Saúde do Trabalhador no Brasil. Revista Brasileira de Saúde Ocupacional, 38, 280-291.

Neves, M. Y., Brito, J., \& Athayde, M. (2010). Mobilização das professoras por saúde. In Raab, G. D. M., \& Rocha, L. E. (Orgs.), Saúde mental no trabalho: da teoria à prática (pp. 248-270). São Paulo: Roca. Neves, M. Y., Seligmann-Silva, E., \& Athayde, M. (2004). Saúde mental e trabalho: um campo em construção. In Figueiredo, M., Athayde, M., Brito, J., \& Alvarez, D. (Orgs.). Cenários do trabalho: subjetividade, movimento e enigma (pp. 19-49). Rio de Janeiro: DP\&A.

Oddone, I., Marri, S., Gloria, S., Briante, G., Chiattella, M., \& Re, A. (1986). Ambiente de trabalho: a luta dos trabalhadores pela saúde. São Paulo: Hucitec.

Oddone, I., Re, A., \& Briante, G. (1981). Redécouvrir l'expérience ouvrière: vers une autre psychologie du travail? Paris: Messidor/Éditions Sociales.

Santos, M. (2004). 0 projecto de uma sociedade do conhecimento: de Lev Vygotski a práticas efectivas de formação contínua em Portugal. Tese de doutorado. Faculdade de Psicologia e de Ciências da Educação da Universidade do Porto, Porto.

Schwartz, Y. (2000a). A comunidade científica ampliada e o regime de produção de saberes. Trabalho e Educação, Belo Horizonte, 7, 38-46.

Schwartz, Y. (2000b). Le paradigme ergologique ou un métier de philosophe. Toulouse: Octarès.

Schwartz, Y. (2010). Trabalho e Ergologia. In Y. Schwartz, \& L. Durrive (Orgs). Trabalho e Ergologia: conversas sobre a atividade humana (pp.25-46). $2^{\mathrm{a}}$ ed. rev. e ampl. Niterói: Editora da Universidade Federal Fluminense.

Silva, E. F. (2003). Trabalhadores/as de escola e construção de uma "comunidade ampliada de pesquisa": a busca da promoção da saúde a partir dos locais de trabalho. Tese de Doutorado. Escola Nacional de Saúde Pública Sergio Arouca, Fundação Oswaldo Cruz, Rio de Janeiro.

Silva, E. F., \& Athayde, M. (2001). Saúde? O mestre faltou! Questionando a (não) participação dos sindicatos de trabalhadores de educação na luta pela saúde do trabalhador na Paraíba. (2001). In M. Athayde, M. E. Barros, J. Brito., \& M. Y. Neves (Orgs.), Trabalhar na escola? Só inventando o prazer (pp. 279-303). Rio de Janeiro: Edições IPUB-CUCA.

Silva, E. F., Brito, J., Athayde, M., \& Neves, M. Y. (2009). A promoção da saúde a partir das situações de trabalho: considerações referenciadas em uma experimentação com trabalhadores 
de escolas públicas. Interface - Comunicação, Saúde, Educação. Botucatu. Disponível em: <http:// www.scielo.br/pdf/icse/v13n30/v13n30a10.pdf>>. Acesso em: 17 abr. 2015.

Teiger, C., \& Daniellou, F. (1987). Formation à l'analyse de l'activité et rapport au travail. In C. Dejours (Org.), Plaisir et souffrance dans le travail (pp. 77-94). Paris: AOCIP/CNRS.

Teiger, C., \& Lacomblez, M. (2007). Ergonomia, formações e transformações. In P. Falzon (Org.), Ergonomia (pp. 587-602). São Paulo: Edgard Blücher.

Teiger, C., \& Lacomblez, M. (Orgs.). (2013). (Se) Former pour transformer le travail: dynamiques de constructions d'une analyse critique du travail. Québec/Bruxelles: PUL/ETUI.

Teiger, C., \& Laville, A. (1991). L'aprentissage de l'analyse ergonomique du travail, outil d'une formation pour l'action. Travail et Emploi, 47, 53-62.

Vincenti, A. (1999). Ivar Oddone, intellectuel organique et chercheur hétérodoxe. Les territoires du travail: les continents de l'expérience. Marseille, 3, 33-42.

Vygotsky, L. S. (1984). A formação social da mente. São Paulo: Martins Fontes.

\section{NOTAS}

1. O Programa de Formação foi elaborado em razão de uma demanda formulada pelo Sindicato de Profissionais de Educação do estado do Rio de Janeiro a pesquisadores de um centro de pesquisa brasileiro (Fundação Oswaldo Cruz). A partir daí firmou-se uma parceria interinstitucional (centros de pesquisa e sindicatos) e interestadual, sendo também desenvolvido em João Pessoa Paraíba (Brito \& Athayde, 2003; Costa, 2004; Neves, Brito \& Athayde, 2010). Ele contou nos primeiros anos com o financiamento da Agência Canadense para o Desenvolvimento Internacional - Fundo de Igualdade de Gênero, tendo como proponente a Associação Brasileira de Pós-Graduação em Saúde Coletiva.

2. Diferentes contribuições teóricas, resguardadas as suas diferenças, fundamentaram este Programa de Formação, tais como a Ergonomia da Atividade, a Psicodinâmica do Trabalho e a Clínica da Atividade, orientadas pela démarche ética e epistemológica da Ergologia. Para um detalhamento dessas contribuições indicamos os artigos de Brito e Athayde (2003), França, Athayde, Muniz, Neves \& Brito (2013) e Neves, Brito \& Athayde (2010).

3. Comunidade Ampliada de Pesquisa (CAP) foi a primeira denominação sugerida por Jussara Brito e Milton Athayde (2003). Em texto mais recente (Athayde, Zambroni-de-Souza \& Brito, 2014) propuseram uma atualização desta denominação para Comunidade Ampliada de Pesquisa e Intervenção (CAPI), sinalizando, na própria nomenclatura, a dimensão da intervenção, já afirmada anteriormente. Reiterou-se no vocábulo comunidade como tributário de iniciativas importantes na tradição da Educação Popular no cenário brasileiro, cujas experiências afirmaram a importância do diálogo entre o conhecimento científico e os saberes das camadas populares. Freire (1987) já fazia uso da expressão círculos de investigação temática para falar do dispositivo de formação baseado no debate entre saberes distintos.

4. Estaremos nos referindo aos trabalhadores e trabalhadoras que realizam suas atividades em escolas de ensino fundamental sempre no feminino, devido ao fato de sua composição ser majoritariamente de mulheres. Dessa forma, procuramos tornar visível desde já a divisão sexual do trabalho que é operada histórica e socialmente.

5. Todos esses Encontros (como os que ocorreram no curso) foram devidamente registrados em gravações de áudio e vídeo, cujos materiais possibilitaram, posteriormente, a confecção de um vídeo intitulado "Trabalhar na escola? Só inventando o prazer", que compunha um conjunto de 
ferramentas envolvendo os Cadernos de Textos, de Métodos e Procedimentos e de Relatos de Experiências.

6. Nomenclatura clássica nos movimentos sociais populares brasileiros nos anos 1970-90, remetendo a uma diferenciação com os militantes que ocupavam a direção formal dos movimentos.

7. Nessa época existiam 91 escolas no município de João Pessoa.

8. Usamos tal vocábulo seguindo a proposta de Ergoformação (Durrive, 2010), que visa facilitar Encontros dos trabalhadores entre si e com o seu trabalho.

9. A ideia era de que participassem ativamente desses Encontros as trabalhadoras das escolas, equipe de investigadores, multiplicadoras e militantes sindicais.

10. Não tendo ainda realizado o curso de formação.

11. Que se encontra alojado no portal da Fiocruz: http://capescola.ensp.fiocruz.br

12. Tal questão foi enfrentada com rigor por Santos (2004), que, ao analisar diferentes práticas de formação, encontrou situações em que trabalhadores experientes, ao assumirem a responsabilidade por programas de formação de outros trabalhadores, não levavam suficientemente em consideração a própria experiência, privilegiando o ensino de protocolos.

\section{RESUMOS}

O artigo analisa a experiência do Programa de Formação em Saúde, Gênero e Trabalho nas Escolas, desenvolvido no Brasil, e do seu dispositivo metodológico Comunidade Ampliada de Pesquisa e Intervenção (CAPI). O Programa foi concebido como um meio para desenvolver a capacidade de compreender $\leftrightarrow$ transformar as relações entre trabalho, processos de subjetivação e saúde-doença nas escolas, com base no diálogo-confrontação entre o conhecimento científico e o saber oriundo da experiência das trabalhadoras de escolas. As principais contribuições epistemológicas e teórico-metodológicas foram o Modelo Operário Italiano (MOI) e a démarche ergológica. Especificamente na cidade de João Pessoa (Paraíba), profissionais de pesquisa e trabalhadoras empreenderam uma ação compreensivo-transformadora das situações nocivas que, mesmo considerando os desafios enfrentados, mostrou a potencialidade dessa experimentação na promoção da saúde, nas mudanças das condições de trabalho das escolas e no fortalecimento da capacidade política de intervenção das trabalhadoras.

Este artículo examina la experiencia del Programa de Formación en Salud, Género y Trabajo en las Escuelas, realizado en Brasil, y su dispositivo metodológico - Comunidad Ampliada de Investigación y Intervención (CAPI). El programa fue concebido como un medio para desarrollar la capacidad de comprender $\leftrightarrow$ transformar las relaciones entre trabajo, procesos de subjetividad y salud-enfermedad en las escuelas, y se basa en el diálogo-confrontación entre el conocimiento científico y el conocimiento derivado de la experiencia de trabajadoras de escuelas. Las principales contribuciones epistemológicas y teóricas-metodológicas fueron el Modelo obrero Italiano (MOI) y la perspectiva ergológica. Profesionales de la investigación y trabajadoras de João Pessoa (Paraíba) realizaron una acción comprensivo-transformadora de situaciones dañinas que, pese a los desafíos, mostró el potencial de esta experiencia en la promoción de la salud, en los cambios de las condiciones de trabajo de las escuelas y el fortalecimiento de la capacidad de intervención política de las trabajadoras. 
L'article examine l'expérience du Programme Formation en Santé, Genre et Travail dans les Écoles, développé au Brésil, et son dispositif méthodologique Communauté Élargie de Recherche et Intervention (CAPI). Le Programme est présenté comme un moyen de développer la capacité de comprendre $\leftrightarrow$ transformer les relations entre travail, processus de subjectivation et santémaladie dans les écoles. Il s'est fondé sur le dialogue-confrontation entre les connaissances scientifiques et les connaissances issues de l'expérience des travailleuses dans les écoles. Le Modèle Ouvrier Italien (MOI) et la perspective ergologique sont les principales contributions épistémologiques et théorico-méthodologiques. Les professionnels de la recherche et les travailleuses de João Pessoa (Paraíba) ont entrepris une action compréhensive et transformatrice des situations dangereuses qui, malgré les difficultés, a montré le potentiel de l'expérimentation sur les plans de la promotion de la santé, des changements des conditions de travail dans les écoles et du renforcement de la capacité d'intervention politique des travailleuses.

The current paper analyzes the experience with the Program of Health, Gender and Labor Formation in Schools, developed in Brazil, and its methodological basis - Extended Research and Intervention Community (CAPI). It was conceived as a means to develop the ability of understanding-changing the relationships among labor, processes of subjectivation and healthillness within schools, according to the dialogue-confrontation between the scientific knowledge and the knowledge resulting from the experience of female workers in schools. The main epistemological and theoretical-methodological contributions came from "Modelo Operário Italiano (MOI)" - Italian Worker Model - and from the ergological demarche. Specifically in the city of João Pessoa (Paraíba), research professionals and female workers ventured in a changingcomprehensible action over the harming situations. Even taking under consideration the challenges that were faced, this action has shown the potential of such experiment on promoting health, on changing the labor conditions in schools and on reinforcing the female workers' political intervention capacity.

\section{ÍNDICE}

Keywords: formation, labor in school, health, extended research and intervention community, ergology

Palavras-chave: formação, trabalho na escola, saúde, comunidade ampliada de pesquisa e intervenção, ergologia

Palabras claves: formación, trabajo en la escuela, salud, comunidad ampliada de investigación e intervención, ergología

Mots-clés: formation, travail scolaire, santé, communautés élargies de recherche et intervention, ergologie

\section{AUTORES}

\section{MARY YALE NEVES}

Grupo de Pesquisas Gestão, Trabalho e Atividade - GESTA, Departamento de Psicologia - Instituto de Psicologia, Universidade Federal Fluminense, Rua Clarice Índio do Brasil, 30 apt 803, Botafogo, CEP 22.230-090, Rio de Janeiro, RJ - Brasil

myale@uol.com.br 


\section{HÉLDER PORDEUS MUNIZ}

Grupo de Pesquisas Gestão, Trabalho e Atividade - GESTA, Departamento de Psicologia - Instituto de Psicologia, Universidade Federal Fluminense, Rua Pinheiro Machado, 99/508, Laranjeiras, Rio de Janeiro - RJ. Cep 22231-090.

heldermuniz@uol.com.br

\section{EDIL FERREIRA DA SILVA}

Programa de Pós-graduação em Psicologia da Saúde e Programa de Pós-graduação em Serviço Social, Universidade Estadual da Paraíba (UEPB), Av. Sapé, 434 - Apto 502, Manaíra, João Pessoa, PB - Brasil edilsilva@uol.com.br

\section{JOANA DAR'K COSTA}

Grupo de Pesquisa Estudos Literários Lusófonos, Departamento de Letras, Universidade Estadual da Paraíba - CAMPUS VI, Rua Aberlardo Pereira dos Santos, 76, Centro - Monteiro-PB, Cep 585000-000

joanadc2@yahoo.com.br

\section{JUSSARA BRITO}

Grupo de Pesquisa e Intervenção em Atividade de Trabalho, Saúde e Relações de Gênero, Escola Nacional de Saúde Pública Sergio Arouca (ENSP), Fundação Oswaldo Cruz (FIOCRUZ), Pesquisadora do CNPq, Rua Leopoldo Bulhões, 1480, Manguinhos - Rio de Janeiro - RJ. , Brasil, CEP: 21041-210

jussara@ensp.fiocruz.br

\section{MILTON ATHAYDE}

Grupo de Pesquisa Actividade, Instituto de Psicologia, Universidade do Estado do Rio de Janeiro, Pesquisador do CNPq, Rua Duvivier, 18, ap. 601, Rio de Janeiro - RJ, Brasil athayde.milton@gmail.com 